\title{
Balanced news for long-term growth
}

\author{
China has the world's most ambitious plan to expand nuclear power production to boost its economic growth. \\ Now research shows that a concerted effort to control news framing may be playing an essential role in cultivating \\ public acceptance of nuclear risk, helping to ensure sustained development of the nuclear power industry.
}

\section{Lei Huang and Yang Liu}

n 2015, the Chinese government announced that it would work hard to make China's total carbon emissions peak before $2030^{1}$. It can be expected that nuclear energy will play an even more important role in China's low-carbon policy given its readiness for large-scale application compared with renewable energy sources such as solar power, hydropower and biofuels ${ }^{2}$. However, China has long been criticized for not making sufficient efforts to communicate the risks associated with nuclear power production ${ }^{3}$. Writing in the Journal of Risk Research, Hongfeng Qiu and colleagues from Xiamen University report that, taking advantage of the ubiquitous information control by the government, China's state-controlled nuclear power industry has been actively influencing news framing, which mediates the public's reaction to the risks associated with nuclear power ${ }^{4}$.

Qiu and team first conducted small-scale, semi-structured interviews with key figures, such as government officials and journalists, in Yunxiao County, a relatively underdeveloped region in Southern China with a newly constructed nuclear power plant nearby ${ }^{4}$. The interviews identified several strategies that are being used to control information about nuclear risk in the news, including arranging guided tours of well-run nuclear power facilities, selecting designated journalists for exclusive favourable reporting, monitoring online forums and flooding the Internet with government propaganda. Next, the researchers conducted a survey of 500 households in the same region, which showed that the more respondents identified with the news framing on nuclear power, the more they trusted local government to control nuclear risk; greater trust in government was, in turn, associated with lower nuclear risk perception and greater acceptance of the nuclear power plant. Together, these results suggest that active information control that promotes positive news framing has generated public identification with the

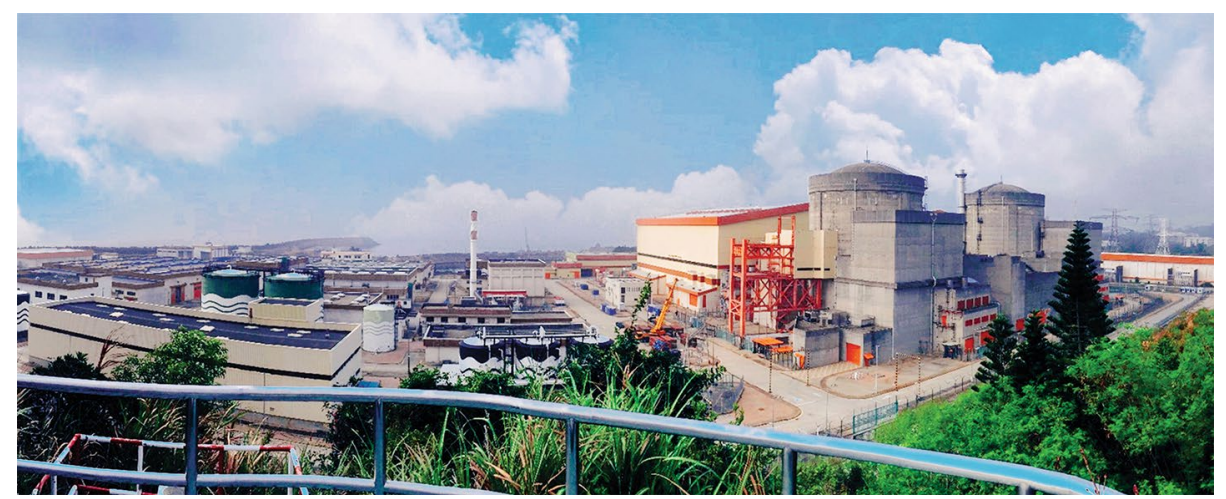

Dayawan nuclear power plant in China. Credit: Lei Huang, Wei Yu

official agenda, enhanced public trust in government and successfully increased public risk acceptance.

The assumption behind the strategy of using news framing to enforce trust-based risk communication is that people cannot understand complex issues such as nuclear power. Therefore, they form or change their attitudes towards the risk of nuclear power by invoking heuristic information such as "Experts or government can be trusted" and "The majority opinion is correct". This is also known as experiential risk processing ${ }^{5,6}$.

Nuclear power technology is indeed highly complex, and China has a strong record of safely operating nuclear power plants without any level two or higher nuclear incidents since $1991^{2}$. Consequently, experiential judgment has very likely dominated public nuclear risk perception in China, especially in underdeveloped regions such as Yunxiao where information flows mostly through government-controlled news outlets. In addition, Qiu and team controlled for many factors influencing risk perception and acceptance such as demographics, intuitive risk judgement, benefit perception and procedural justice awareness, making their quantitative analysis robust and convincing ${ }^{7,8}$.

Qiu et al. neither defend nor denounce the practice of allowing public access to only positive information on nuclear power. However, in the age of social media and rapid data sharing, news framing and censoring may damage public trust of the government on critical issues. Therefore, Qiu and team argue that healthy scepticism cultivated by objective and transparent information sharing of the potential risks of nuclear power may be beneficial to the long-term development of China's nuclear power industry 4 .

For example, the rapid spread of China's nuclear facilities has also expanded the public's awareness and knowledge of nuclear power. Unlike people from underdeveloped regions such as Yunxiao, residents of the affluent coastal cities of China are better educated and more savvy with information technology. They may therefore be more likely to actively seek information related to their well-being in the event of a nuclear accident. Under such circumstances, experiential risk processing would give way to analytic risk processing, by which highly motivated people have the desire and capacity to form judgments, and change their attitudes by actively attending to and cognitively elaborating persuasive argumentation $^{6}$.

Moreover, popular social media platforms such as WeChat and TikTok allow individuals to quickly create and disseminate 
uncensored information before it can be denied public access by internet monitoring authorities. In the past, such information has provoked public protests and anger, forcing the government to adjust their nuclear development plans. For example, the public's approval of nuclear power dropped sharply soon after the Fukushima Nuclear Accident ${ }^{8}$. Since then, several nuclear projects including the Jiangmen nuclear waste facility in 2013 and the Lianyungang nuclear fuel cycle project in 2016 have been suspended or cancelled due to public opposition ${ }^{9-11}$. These incidents represent just a few examples of why decision-makers must re-examine China's current risk communication strategy, which holds that ensuring absolute public trust in the government's actions is in the public's best interest for major policy decisions such as nuclear power.

The benefit of a more balanced and transparent risk communication strategy can be seen in the current COVID-19 outbreak in China. The initial information censoring and control measures taken by the Wuhan local government were ineffective and only provoked rumour, panic and distrust in the government as people worldwide quickly learned about the devastating effects of the virus through images, videos and unofficial reports distributed through various social media platforms. Fortunately, the government promptly adjusted its risk communication strategy by providing up-to-date information on tests, confirmed cases and deaths related to COVID-19. Such transparency eventually helped regain public support for the aggressive lockdown and social distancing measures to bring the pandemic under control and avoid a catastrophic loss of human life and collapse of the domestic economy ${ }^{12}$.

The study from Qiu et al. demonstrates the success of a news-framing nuclear risk communication strategy in the Yunxiao region ${ }^{4}$. However, rapidly evolving new technologies and social media platforms may break the information barrier imposed by the Chinese government in the foreseeable future. Consequently, policymakers may need to begin reforming current methods of risk communication and encouraging more robust dialogue with the public about nuclear power.
Lei Huang (D) $1 \times$ and Yang Liu (D) $2 \bowtie$

${ }^{1}$ State Key Laboratory of Pollution Control and Resource Reuse, School of the Environment, Nanjing University, Nanjing, P. R. China. ${ }^{2}$ Gangarosa Department of Environmental Health, Rollins School of Public Health, Emory University, Atlanta, GA, USA.

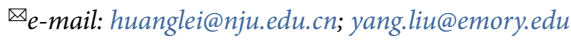

Published online: 29 June 2020

https://doi.org/10.1038/s41560-020-0649-y

\section{References}

1. Enhanced Actions on Climate Change (in Chinese) (National Development Reform Commission, 2016); https://www4.unfccc. int/sites/ndcstaging/PublishedDocuments/China\%20First/ China\&\#39;5\%20First\%20NDC\%20Submission.pdf

2. Wu, Y. Energy Policy 101, 484-491 (2017).

3. Wu, Y. et al. Proc. Natl Acad. Sci. USA 116, 17673-17682 (2019).

4. Qiu, H., Weng, S. \& Wu, M. S. J. Risk Res. https://doi.org/10.1080/ 13669877.2020.1749116 (2020).

5. Slovic, P., Finucane, M. L., Peters, E. \& MacGregor, D. G. Risk Anal. 24, 311-322 (2004).

6. Huang, L., Bi, J., Zhang, B., Li, F. \& Qu, C. Front. Env. Sci. E. 4, 73-81 (2010).

7. Slovic, P. Science 236, 280-285 (1987).

8. Huang, L. et al. Proc. Natl Acad. Sci. USA 110, 19742-19747 (2013).

9. Yang, H., Xia, J. \& Flower, R. J. Nature 542, 414-414 (2017).

10. Xia, D. et al. Energy Policy 132, 208-215 (2019).

11. Huang, L. et al. Energy Policy 120, 294-301 (2018).

12. Zhang, L., Li, H. \& Chen, K. Healthcare 8, 64 (2020). 